\title{
Solar Incentives Planning and Development: A State- of-the-Art Review and Research Agenda
}

Dennis Schiffel

David Posner

Karin Hillhouse

James Doane

Patricia Weis
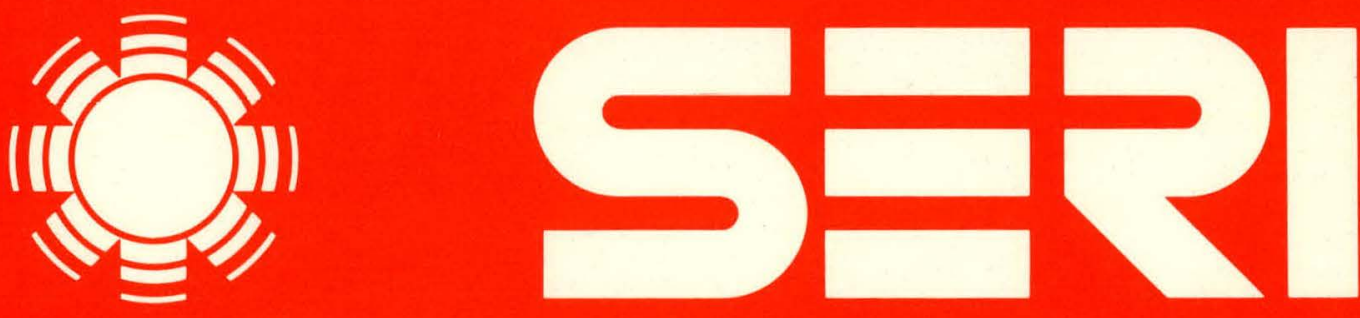

Solar Energy Research Institute

A Division of Midwest Research Institute

1536 Cole Boulevard

Golden, Colorado 80401

Operated for the

U.S. Department of Energy

under Contract No. EG-77-C-01-4042 


\section{DISCLAIMER}

This report was prepared as an account of work sponsored by an agency of the United States Government. Neither the United States Government nor any agency Thereof, nor any of their employees, makes any warranty, express or implied, or assumes any legal liability or responsibility for the accuracy, completeness, or usefulness of any information, apparatus, product, or process disclosed, or represents that its use would not infringe privately owned rights. Reference herein to any specific commercial product, process, or service by trade name, trademark, manufacturer, or otherwise does not necessarily constitute or imply its endorsement, recommendation, or favoring by the United States Government or any agency thereof. The views and opinions of authors expressed herein do not necessarily state or reflect those of the United States Government or any agency thereof. 


\section{DISCLAIMER}

Portions of this document may be illegible in electronic image products. Images are produced from the best available original document. 


$$
18
$$

\section{NOTICE}

This report was prepared as an account of work sponsored by an agency of the United States Government. Neither the United States nor any agency thereof, nor any of their employees, makes any warranty, expressed or implied, or assumes any legal liability or responsibility for any third party's use or the results of such use of any information, apparatus, product, or process disclosed in this report, or represents that its use by such third party would not infringe privately owned rights. 


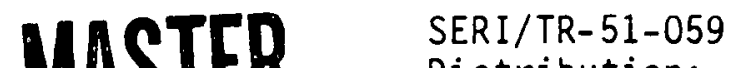 \\ MASTER Oistrintitions \\ See last page}

SOLAR INCENTIVES PLANNING AND DEVELOPMENT:

A STATE-OF-THE-ART REVIEW AND RESEARCH AGENDA

\author{
Dennis Schiffel \\ David Posner \\ Karin Hillhouse \\ James Doane \\ Patricia Weis
}

August 1978
This report was prepared as an account of work sponsored by the United States Govemment. Neither the United States nor the United States Department of Energy, not any of their employees, nor any of their contractors, subcontractors, or their employees, makes any warranty, express or implied, or assumes any legal liability or responsibuity for the accuracy, completeness or usefulness of any information, apparatus, product or process disclosed, of represents that its use would not

infringe privately owned rights. 
This report is the final product of a Policy Analysis Branch task to develop a research plan for analysis of solar energy incentives. Members of the Policy Analysis Branch contributing to the report were Dennis Schiffel, David Posner, Karin Hillhouse, James Doane, and Patricia Weis.

The authors wish to acknowledge the helpful comments on the initial draft of the report provided by $H$. Craig Peterson (Utah State University), Fred Boercker (Oak Ridge National Laboratory), Larry Blair (Oak Ridge Associated Universities), Richard 0'Toole (Jet Propulsion Laboratory), Barbara Farhar (Solar Energy Research Institute), and Susan Persson (Solar Energy Research Institute). The authors also wish to thank the Word Processing staff and particularly Barbara Glenn for her editorial assistance.

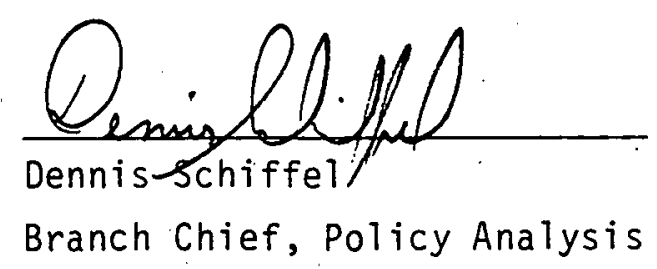

Approved for:

SOLAR ENERGY RESEARCH INSTITUTE 
Executive Summary

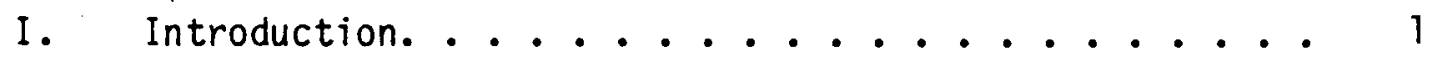

A. Objective.................. 1

B. Background. .................. 1

C. Approach.................. 4

II. An Informal Framework for Assessing Incentives. . . . 6

A. Context for Assessing Incentives ....... 6

B. Incentives. ............. 9

C. The Informal Framework. ........... 10

III. Literature Review ........... 19

A. Introduction. ............... 19

B. Diagnosis: symptoms. . . . . . . 20

C. Diagnosis: Causation .......... 26

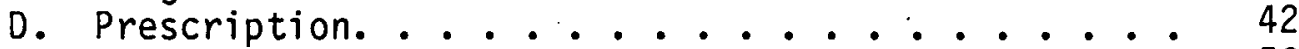

E. Evaluation. ............. 50

F. Major Requirements for Further Re search . . . . . 53

IV. Research Agenda .............. 56

A. A Note on Research Planning . . . . . . . 56

B. Setting Research Priorities ......... 58

C. The Agenda. ............. 60

D. Summary ................. 70 


\section{ABSTRACT}

This report develops a research agenda designed to assist the Department of Energy in the planning and development of solar energy incentives. A fourelement framework for assessing solar incentive policies is presented. In the context of this framework, the available solar research relevant to incentives for solar energy is reviewed. Comparing the requirements identified in the framework and the contents of completed research, major gaps in the literature on solar incentives are identified. An agenda for research is then proposed to eliminate these gaps and to provide information for constructing effective solar energy incentives. 
SOLAR INCENTIVES PLANNING AND DEVELOPMENT:

A STATE-OF-THE-ART REVIEW AND RESEARCH AGENDA

Final Report

EXECUTIVE SUMMARY

\section{A. OVERVIEW}

This report presents a framework for analysis and evaluation of solar energy incentives, a review of the literature related to solar incentives development, and an agenda of needed research. The research agenda is designed to help the Department of Energy develop incentives that will effectively advance the commercial development of solar energy technologies. The proposed research agenda when completed will also help determine the level of expenditures which the government should invest in solar energy incentives.

\section{B. A FRAMEWORK FOR ASSESSING INCENTIVES}

Incentives are a special case of government intervention to improve on private market results, and they can be designed and evaluated in terms of their effectiveness and efficiency in accomplishing that purpose. A basic assumption of this study is that the private market mechanism will continue to be the primary mechanism by which new technologies diffuse through society. A four-element framework for designing incentives consists of the following.

(1) A first diagnostic element to identify the solar energy products and markets in which there is a divergence between socially desirable results and results produced by the private sector. (Is there a problem that should cause private results to be changed?) 
(2) A second diagnostic element to identify the causes of each divergence between the actions of the private sector and socially optimal results. (What is the source of the problem?)

(3). A prescriptive element, based on the diagnosis in steps one and two and on an examination of the corrective tools available to the government, to match the incentive to the problem. (Can any incentive be effective, and which would be most effective?)

(4) A monitoring and evaluative element to record and analyze the results of the incentives employed, so that the lessons of experience may be incorporated in revised and future incentives. (How well did the incentive work and what would have worked better?)

\section{RESULTS OF LITERATURE REVIEW}

The available solar energy research was reviewed to determine the extent to which adequate answers to the question posed in the assessment framework are currently available. From the review, it can be observed:

- It is not currently possible to define the socially optimal level of investment in solar technologies because neither the social benefits to be gained from solar utilization nor the costs necessary to achieve solar utilization have been adequately defined for analyzed;

- It is not currently possible to identify the best incentives to modify private investment decisions with respect to invention, development, manufacture, or adoption of solar energy devices and systems; 
- It is not currently possible to identify those solar technologies which will satisfy social, economic, and technical criteria for substantial governmental support at particular stages in the technology product development process. Policymakers and solar decisionmakers have not articulated such criteria fully or explicitly; and

- It is not currently possible to specify the procedures by which society will select and implement al ternative energy options.

In addition to the need to fill specific research gaps, the literature review uncovered the need for coordinated research to develop an integrated solar energy incentives strategy. Too often, research on solar policy questions has been conducted on a fragmented basis with little understanding of how individual research projects are related. A large portion of completed research has been oriented toward providing answers to immediate policy questions. As a result, the capabilities to address the implications of major solar policy decisions are lacking.

\section{RESEARCH AGENDA}

The research agenda organizes proposed research into the following six broad categories:

- specify social benefits and costs to be expected from greater utilization of solar energy;

- establish a strategic decision-oriented framework for deriving necessary incentives research on each solar energy technology; 
- examine results of previous product development efforts to identify critical factors required in an incentive;

- specify the objectives, design, and timing of particular incentive options;

- analyze the implementation experiences of existing solar incentives and design evaluation programs for future incentives; and

- design model implementation program guidelines and regulations.

Within each category, specific research objectives have been identified.

The research agenda is organized to provide a method for (1) determining if gaps in knowledge are being filled by appropriate research and (2) relating various pieces of research to an overall structure of the knowledge and research needed for effective solar incentive planning and development. The ordering of the six research categories also reflects priority assessment. The specification of priorities along with the identification of needed research and the statement of research objectives provides the rudiments of a plan for solar incentive development.

While this report has concentrated on identifying research information needed to design appropriate incentives, it is also clear that an institutional mechanism must be found to courdinate and oversee the specific studies that might be undertaken under the proposed research agenda. 
SOLAR INCENTIVES PLANNING AND DEVELOPMENT:

A STATE-OF-THE-ART REVIEW AND RESEARCH AGENDA

\section{INTRODUCTION}

\section{A. OBJECTIVE}

The objective of this report is to develop an agenda for research on the analysis and evaluation of incentives for individuals and organizations to develop and adopt solar energy technologies. The report will help the Department of Energy identify the proper scope for government incentives to solar energy and design effective and efficient incentives within that scope.

\section{B. BACKGROUND}

Al though scattered efforts to develop and utilize solar energy have existed for many years, a major stimulus for such efforts was the sharp increase in energy prices following the 1973 OPEC 017 embargo. After 1973, federal government support for solar energy research, development, and demonstration was rapidly increased.

Al though hampered by a lack of analytical information about solar eneryy diternatives, the Congress enacted a series of laws to promote solar energy. For example, the Solar Heating and Cooling Demonstration Act of 1974 (PL 93-409) established the interim objective of accelerating solar energy development. The Act called "for the demonstration within a three-year period of the practical use of solar heating technology, and to provide for the development and demonstration within a five-year period of the 
practical use of combined heating and cooling technology."1,2 Similarly, the Solar Energy Research, Development, and Demonstration Act of 1974 (PL 93-473) declared a policy to "preserve a vigorous and viable program of research and resource assessment of solar energy as a major source of energy for our national needs" and to "provide for the development and demonstration of practicable means. to employ solar energy on a commercial scale." 3 The Energy Conservation and Production Act of 1976 (PL 94-385) authorized the Department of Energy (then the Federal Energy Administration) to "carry out a program to develop the policies, plans, implementation strategies, and program definitions for promoting accelerated utilization and widespread commercialization of solar energy and to provide overall coordination of Federal solar energy commercialization activities." 4

142 U.S.C.S. Section 5501 (b)

${ }^{2}$ The act also provided for the following actions to accelerate commercialization of solar heating and cooling systems: (1) dissemination of information to federal, state, and local authorities; the building industry and related segments of the economy; the scientific and technical community; and the public at large; (2) evaluation of laws, codes, ordinances, and practices which might interfere with commercial and residential solar heating and cooling; and (3) appraisal of the necessity of solar residential incentives. (See 42 U.S.C.S. Section 5510.)

$3_{42}$ U.S.C.S. Section 5521 (b) (1) (2)

$4_{42}$ U.S.C.S. Section 6801 
A dominant theme of the federal legislation is the desire to accelerate the commercialization of solar energy technologies. 5 The questions that this theme raises include:

- At what rates are solar energy technologies presently being commercialized?

- What effects do current government policies and incentives have on commercialization rates?

- What factors inhibit or promote the commercialization of solar energy technologies?

- Given their respective rates of technical development, what are the socially optimal rates of commercialization. for the various solar technologies?

- What tools are available to the government that could be employed to accelerate the commercialization of solar technologies?

- How will the private sector react to alternative federal policies and incentives toward solar?

5 "Commercialization" is defined, for the purposes of this document, as the establishment of both a viable private demand for solar energy systems and an industry capable of meeting this demand. This definition implies that the demand for solar energy systems and the responding industry can exist without government subsidy, although some subsidies may be justified to account for environmental and social benefits which are not included in market prices. 
Al though some research has been conducted on these questions, a substantial amount of information is still needed. ${ }^{6}$ If the premise is accepted that the best decisions are informed decisions, it is essential to identify and fill gaps concerning solar energy commercialization and the proper scope for government intervention therein.

\section{APPROACH}

The approach adopted in this report is first, to describe the rudiments of a conceptual framework which can be used to analyze and evaluate solar incentives. This framework, presented in Chapter II, itself suggests needed research on incentives. Second, a review of the 1 iterature is undertaken in Chapter III to assess what is known about solar incentives. Information gaps are Identified by comparing the information requirements identified in the conceptual framework with the information currently available as reflected in the state-of-the-art literature review. Chapter IV presents an agenda for solar incentives research to fill the gaps.

As the agency with responsibility for formulating energy policy, the Department of Energy must make critical assessments of solar energy technologies, possible incentives, and strategies for implementation. A basic premise of this report is that timely completion of analyses and the evaluations of solar energy policy options will help in the formulation of solar incentive policies. The report serves as a planning guide for the conduct of the needed pollcy research.

\footnotetext{
${ }^{6}$ The available research has been largely supported by the National Science Foundation, the former Federat Energy Administration, the former Energy Research and Development Administration, the Department of Energy and a few private groups.
} 
Throughout this report, the positive value of analysis in the policy formulation process is emphasized. This should not be misinterpreted as suggesting that analysis, by itself, is the key to desirable solar incentive policies. The results of analysis are only inputs to the decisionmaking process and need to be placed in a political and social context. 


\section{I1. AN INFORMAL FRAMEWORK FOR ASSESSING INCENTIVES}

\section{A. CONTEXT FOR ASSESSING INCENTIVES}

In constructing the research agenda, it is important to understand the role of government intervention in markets in general, and in the solar commercialization process in particular. Historically in the United States, private market forces have performed the necessary R\&D and commercialization activities to make the United States a world leader in product and process innovations. The primary vehicles for this innovation and diffusion have been private incentives offered to producers and consumers of goods and services (e.g., the pursuit of profits and the maximization of individual welfare).

Yet the private market mechanism sometimes stops short of producing all socially desirable innovations. For example, the level of basic research activities, financed by private firms often constitutes, from a societal perspective, an underinvestment in basic research. This is not to say that private investment in research is small in an absolute sense--underinvestment refers to a condition where research projects whose overall benefits exceed their overall costs are not undertaken. The underinvestment does not reflect any irrationality or timidity on the part of the managers of private research--they can be shown to be responding rationally to their expectations of private benefits and costs. Underinvestment in research is a misallocation of resources only from the viewpoint of society at large, and it occurs only when society as a whole can capture benefits or prudently accept risks beyond the abilities of private firms. For example, a breakthrough in basic understanding of the causes of cancer would have tremendous social value, yet it would be very difficult for a private laboratory to support the necessary research on its own. 
At least two major factors contribute to this underinvestment in research.

- An improved understanding of fundamental scientific principles is neither marketable nor patentable. A private organization which funds a basic research program has little assurance of capturing for itself a sufficient share of the benefits, should the program succeed, to recoup $i$ ts investment. The more basic a body of research, the less "capturable" its results are likely to be. And, as the probability of capturing benefits in excess of costs declines, private investment in research declines.

- A great deal of uncertainty is attached to whether a research program will succeed, when $1 t$ might succeed, or how much it will cost. As this uncertainty increases, private investment in research tends to decrease.

Nuclear fusion provides a good illustration of the second point. The payoffs to a successful research program are enormous, but the expected cost and the risk of failure are so great that private investors could not prudently undertake such a program.

In the United States (and in other countries) the responses to these circumstances have been to invest publicly in basic research, and the underinvestment argument motivates the annual expenditure of billions of federal research dollars through specialized agencies such as the National. Science Foundation as well as the mission agencies (NIH, NASA, DOE, etc.). 
The divergence between the societal benefits to be derived from additional basic research and the benefits (or lack thereof) accruing to private institutions engaged in R\&D is symptomatic of a larger issue. That is, individual decisionmaking units rarely take into account the full scope of benefits and costs resulting from their actions. Many decisions or actions have "spillover" or external consequences which fall on individuals or groups not directly involved in the decision or action. An example involving technology utilization, as distinct from research, is where an upstream community decides to dump untreated waste water into a river to minimize its water treatment costs. However, that decision imposes costs on downstream communities which use the river for drinking water and irrigation. The socially best solution would be one that minimized the total water treatment costs of both communitites. The upstream community is unlikely, however, to invest in treatment facilities which reduce total costs if a large portion of that cost reduction occurs downstream. Al though this is a case of public rather than private institutions underinvesting in a beneficial technology, the cause is similar-exclusion from the decision process of some of the socially relevant benefits.

The point is: The optimizing behavior of individual decision units (whether public or private, individuals or groups) may not produce results that are optimal to society as a whole. This possibility exists whether the activity involved is research, development, or investment (in either production facilities or applications). Further, the divergence between actual behavior is unlikely to correct itself because there is no reason for individual decision units to act contrary to existing incentives as they perceive them. The social case for government intervention to improve on private market results by changing the reward structure faced by individual decision units rests on this empirically observable fact. Note that the divergence does not by 
$i$ tself justify government intervention. The effectiveness in removing the divergence and the costs to society of doing so must first be determined. That is, unless resources can be reallocated by government to produce a net gain in social welfare over the existing situation, government intervention is not warranted. This basis for government intervention has two important implications for the evaluation of solar incentives.

- It should not automatically be assumed that government intervention in the form of an incentive will make things better. It should first be established that an underinvestment or misallocation of resources has occurred and that government incentives are the best way to correct it.

- The analysis of private market performance in solar energy based on existing privately perceived incentives, and the design of effective and efficient government incentives are logically inseparable. That is, where an underinvestment is identified, its causes must be understood; and a course of government action to correctly modify private behavior must be determined.

\section{B. INCENTIVES}

For the purposes of this report, "incentives" will cover a broad range of government actions to modify the results of private decisions with respect to development and commercialization of solar technologies. Included in this range are actions whosc influence on results is indirect, through changing the process by which a decision is reached, as well as those that work directly by changing the rewards or costs of specific private actions. An example of an indirect incentive is an attempt to increase private awareness of the life-cycle costs of energy systems, either by 
requiring that 1 ife-cycle calculations be performed (i.e., a change in institutional rules) or by providing such a service to decisionmakers (a change in information). A direct incentive would change the effective private life-cycle cost of a solar system by a variety of methods: tax credits, low-interest or guaranteed loans, assistance with design or installation, etc.

\section{THE INFORMAL FRAMEWORK}

Whether the approach is direct or indirect, incentives are a special case of government intervention to improve on private market results, and they can be designed and evaluated in terms of their effectiveness and efficiency in accomplishing that purpose. A four-element framework for performing this design consists of:

- A diagnostic element to determine if there is any room for improvement (Should private results be changed?);

- A second diagnostic element (if there is room for improvement) to identify the causes of divergence between privately and socially optimal results (What is the source of the problem?);

- A prescriptive element, based on the diagnosis in step two and an examination of the corrective tools available to the government, to match the incentive to the problem (Can any incentive be effective, and which would be most effective?); and

- A monitoring and evaluative element to record and analyze the results of the incentives employed (and of previous incentives), so that the lessons of experience may be-incorporated in revised and future incentives (How well did the incentive work? What would have worked better?). 


\section{Diagnosis: Symptoms}

The first element in a framework for assessing incentives is a diagnostic one, addressed to the question: What is the problem or opportunity that requires a change in private behavior? In the case of incentives for solar energy research, development, and utilization, the problem can be characterized as the assumed failure of private markets to define, develop, and utilize solar energy technologies at a rate commensurate with the expected net social benefits that implementation of solar energy technologies might confer. This assumption leads in turn to the conclusion that government intervention to modify market behavior is appropriate (i.e., that the public good will be promoted by government intervention to provide incentives to reallocate resources into solar energy research and utilization).

To determine if government incentives are warranted, however, one must move from assumed answers to factual answers to the following questions:

- Have private markets failed to research, develop, or utilize solar energy at socially optimal rates?

- If private markets have failed in any of these respects, is the failure expected to continue?

- Are the social benefits foregone as a result of such failures sufficient to warrant government intervention to correct the failure?

- Can the amount of increase in social benefits expected to result from government intervention be identified explicitiy, so that there is some guidance as to how much should be invested in solar energy incentives? 
Diagnosis: Causation

The second element of the assessment framework is also a diagnostic one. If private markets have underinvested in solar energy from a public or social point of view, it is necessary to understand why they have done so. Why does the collectivity of private decisions diverge from a socially desirable result? It is one thing to know or suspect a social problem or opportunity exists; it is quite another thing to understand the causes. Yet an understanding of cause and effect relationships is essential to the design of truly corrective incentives which will treat the social problem with cures rather than palliatives.

Private market mechanisms and private institutions have provided a steady stream of product and process innovations covering many technologies. Historically they have also provided the means to diffuse these technical improvements throughout society. Obviously, incentives already exist in the private sector for development and diffusion of superior technologies. Hence the question arises: Why and to what degree are these incentives now inadequate (or are they) with respect to solar energy development and utilization?

In attempting to correct a perceived underinvestment by private individuals and institutions the following issues must be resolved.

- How and to what extent does government affect solar energy commercialization by incentives (subsidies) to other energy sources? Examples of these incentives include price regulation below marginal cost of natural gas, depletion allowances for oil and coal, and heavy public support for nuclear research. These and other government actions may have caused the private market to 
avoid solar in spite of its true social advantages. If so, the problem is not a private misreading of costs and benefits, but is instead a failure by government to allow the true benefits of solar to show.

- How are solar energy development and commercialization affected by individuals' and organizations' perceptions of the risks, benefits, and costs associated with alternative energy sources? Individuals may differ on their perceptions of (a) whether there is an energy problem, (b) the riskiness of a new technology such as solar energy, (c) the expected costs of conventional and solar alternatives, and other issues. In part these issues are related to the flow of information to individuals and organizations, their abilities to process and digest information, and their psychological and social attributes (such as risk aversion), all of which affect behavior.

- What causes failures on the part of individuals and organizations to perceive or to consider the social consequences of their individual decisions?

- Do external constraints cause individuals and organizations to act incorrectly in spite of correctly perceived costs and benefits? For example, even if a consumer recognizes the usefulness of 1 ife-cycle costing and knows solar energy life-cycle costs are lower than the life-cycle costs of other energy sources, he may avoid a solar energy system because of lending or insurance practices, or an income constraint. 
- Do regulations designed for other purposes, such as zoning and building codes, dysfunctionally restrict the use of solar energy?

- Do existing energy supply and distribution networks bias individual and organizational decisionmakers against socially optimal adoptions of solar technologies?

\section{Prescription: Incentive Selection}

The third element in the assessment framework is a careful examination of the incentive tools available to government and an assessment of their effectiveness and efficiency in mitigating private market underinvestment in solar energy. A number of different incentives might address a given cause of underinvestment. The problem is to determine which incentive will correct that underinvestment at least cost. For example, despite Congressional intent to accelerate commercialization of solar energy technologies, Congress presumably demands of an incentive that the increased social benefits obtained exceed the costs to the government of the incentive. The explicit intent in providing incentives is to alter private behavior, causing reallocation of resources from other energy sources into solar energy. Incentives must be designed such that, after deducting the social costs of such reallocation, the increase in solar utilization still constitutes a net increase in social welfare.

Several issues and factors which must be considered in designing appropriate solar energy technology incentives have been discussed above. Another important factor is the state of development of a given solar technology. For example, it is quite premature to pursue commercialization of solar satellite power systems or ocean thermal plants because there is no product currently available. On the other hand, solar water heating and solar space heating 
technologies are already being commercialized, with numerous products, manufacturers, and distributors now available. Incentives appropriate for accelerating the deployment of solar space heating will thus be directed toward potential users and will be very different from the research incentives appropriate for solar satellite power systems or ocean thermal energy conversion. In general, both the appropriateness and the effectiveness of solar incentives will depend upon the stages of development of the respective technologies.

The prescriptive element in the framework for assessing incentives raises questions such as:

- What opportunities exist in the current institutional structure to accelerate commercialization of solar technologies through the use of government. incentives?

- Based on past experience, how effective have particular government incentives been for technologies at different stages of development?

- Can incentives be tailored to treat specific causes of private market underinvestment? Specifically, can government incentive programs correct the divergence between private decisionmaking behavior and socially desirable behavior? Aside from changing short-term behavior by immediate application of some incentive, will long-term behavior remain optimal if the incentive is subsequently terminated?

- Given that different incentives should be offered to different solar energy technologies at different stages of development, what should be the distribution of incentives? Given that different incentives generate 
different sets of benefits and costs, what should be the overall incentive strategy across the solar energy technologies?

- Can private decision processes affecting solar energy development and utilization be dissected so that incentives with high leverage can be designed? What parts of decisionmaking behavior must be changed, and how can incentives be focused on the actors whose behavior must be changed?

- Can the reactions of private sector individuals and organizations to specific incentives be predicted?

- Can the costs of incentives be reduced by designing incentives that are self-policing, or otherwise minimize the need for administrative machinery?

- Can incentives be designed which reward only incremental behavior and do not confer windfall gains for actions that would have occurred even without the incentives?

- Does the incentive produce any undesirable side-effects (such as favoring monopoly, discriminating against lowincome corisumers, creating unemployment, etc.)?

\section{Evaluation: Incentive Monitoring}

A fourth element in a framework for assessing incentives is evaluation or post treatment follow-up. To know whether an incentive has desirable or undesirable effects, the responses to the incentive must be monitored and evaluated. Such monitoring may al so improve the design of incentives by forcing greater specification of objectives, key variables, and expected results 
than would otherwise occur in the design phase. Equally important, feedback from the monitoring activity can improve the incentive being monitored as well as future incentives.

Among the issues to be resolved in this fourth element of the assessment framework are:

- Can adequate baseline projections of private actions without incentives be made against which to compare post-incentive results?

- What has already been learned about private market responses to solar incentives from the numerous state incentives or subsidies that have been enacted?

- What should be the evaluation criteria for determining the success of incentives for solar energy technologies?

- Can a data base be assembled that provides for analytic comparisons of different incentives aimed at different technologies and different target groups?

- What are the appropriate mechanisms for monitoring incentives?

This discussion of a framework for assessing incentives has been brief and informal, but there is an extensive literature relevant to the topic. The literature on welfare economics, public choice, the economics of R\&D and technological innovation, R\&D management, and social diffusion are particularly relevant. Studies of past incentives and government subsidies can provide additional perspectives on incentive options. 
The framework discussed above specified the types of information that would help determine both the desirability of government incentives and their likely efficiency and efficacy. The question arises: Is such information available? The next chapter addresses that question. 


\section{LITERATURE REVIEW}

\section{A. INTRODUCTION}

The informal framework described in Chapter II set forth the basic requirements for effective analysis and evaluation of solar energy incentives. Each element of the framework concluded with a review of questions to be answered in formulating incentive options. This chapter reviews completed and ongoing research efforts that have addressed some of these questions.

The review is restricted to literature on solar energy that sheds light on questions raised in the framework. More general bodies of literature which examine the policymaking process for incentives for other technologies are not included in the review. Lessons from this more general literature could usefully be applied in considering solar incentives. However, without further research, this literature will provide general guidance rather than specific incentives or insight directly applicable to solar energy incentives.

The review is organized to follow the elements of the informal framework. The review is intended to highlight significant research, to suggest key methodological problems, and to summarize important conclusions from completed work. Major gaps in current research and future research requirements are summarized at the end of the chapter. 


\section{B. DIAGNOSIS: SYMPTOMS}

The major question to be answered here is: Has underinvestment in solar energy occurred? To answer this question requires knowledge of the extent of private investment in solar energy as well as of the social benefits associated with a higher level of solar energy investment.

A 1 imited amount of effort has been devoted to documenting the extent of current private investment in solar energy technologies. The former Federal Energy Administration has collected data on solar collector manufacturing activity back to 1974 and on manufacturing and sales activity in wind energy conversion systems back to 1975.7 This function is now continued in the DOE Energy Information Administration. 8 These surveys, however, provide only a partial picture of the extent of private market activity. The surveys summarize sales information but do not indicate in what markets solar equipment was used. No information is collected on the extent of private investment in production facilities, research and development, or future private industry plans. This and other information is essential if the extent of current and future private investment in solar energy technologies is to be adequately described.

TSee Solar Collector Manufacturing Activity: July through December 1976, FEA/B-77/135, ApriT 1977, and Wind Energy Conversion Systems Manufacturing and Sales Activity: $19 \overline{75}$ and 1976, FEA/B-77/1 21 .

${ }^{8}$ Departinent of Energy, Solar Collector Manufacturing Activity and Applications in the Residential Sector: January through June 1977, Energy Information Administration, February 1978. 
To estimate the extent of underinvestment in solar energy, some quantitative information on the social benefits that could be realized from a higher level of investment is needed. Assumed social benefits of solar energy have been the driving force behind previously legislated solar incentives. But the assumptions of the past must be replaced by analytical information if a rational solar energy policy is to develop. Numerous solar energy studies have alluded to the expected benefits of solar energy use. ${ }^{9}$ But no study has systematically quantified these assumed benefits for all solar energy technologies. 10 Reduced pollution, reduced depletion of finite resources, insurance against foreign energy curtailments, increased employment, increased government revenues resulting from lower consumption of conventional fuels (which receive government tax subsidies), and other factors have all been suggested as benefits of solar energy utilization. But rigorous tests for or definitions of solar social benefits have not been used. 11

${ }^{9}$ See, for example: (1) Stanford Research Institute, Solar Energy in America's Future, ERDA Contract E104-3-115, March 1977; (2) SRI Internationa T, A Comparative Evaluation of Solar Al ternatives: Implications for Federal R\&D, Draft Report to DOE Solar Working Group, November 1977; and (3) Dennis Costello and David Posner, Solar Heating and Cooling of Buildings Commercialization Report, Prepared by Midwest Research Institute for the Federal Energy Administration, July 1977.

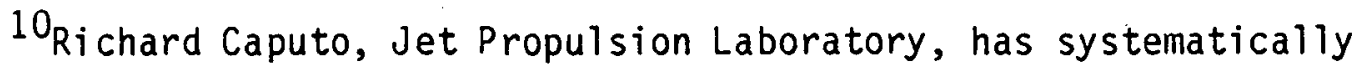
compared the technical, economic, and social impacts of solar space power systems and terrestrial central power systems. See Initial Comparative Assessment of Orbital and Terrestrial Central Power Systems, Final Report to NASA Of fice of Energy Programs, March 197.7.

11 The Department of Energy Technology Assessment Program has initiated a variety of research programs aimed at describing and quantifying the social and environmental benefits of solar energy. Major results from this program are not yet available. See Technology Assessment Program: Decentralized Solar Technologies FY78, DOE Environmenta 1 and Re source Assessment Branch, November $\overline{1977}$. 
Quantitative analysis of the social value of many of these factors poses significant methodological problems. The social values of reduced pollution and reduced dependence on foreign oil, for example, are difficult to quantify. Systematic and creative analysis, however, could lead to credible results. The environmental impacts of conventional energy technologies could be compared to the environmental impacts of solar technologies, ${ }^{12}$ and any net pollution reductions resulting from solar energy use could be assigned a reasonable dollar value. ${ }^{13}$ similarly, the cost of stockpiling oil to provide insurance against foreign curtailments could serve as a measure of the value of accomplishing the same objectives through the use of solar energy technologies. ${ }^{14}$ The Batelle Pacific Northwest Laboratory has quantified the extent of historical government subsidies to conventional energy sources. 15 Whether or not such subsidies cause market prices of these energy sources to refilect the true social cost of using them, they must be accounted for in a complete analysis of the degree to which alternative levels of solar energy utilization reflect a social optimum. It is likely that these subsidies, by creating an artificially low price for conventional energy, contribute to underinvestment in solar technologies.

${ }^{12}$ Some preliminary analyses on the environmental impacts of solar energy technologies have been completed. A review of this literature is currently underway at SERI. Preliminary results are contained in a SERI internal working paper by Kathryn Lawrence.

${ }^{13}$ The costs of reducing pollution by other methods are sometimes used to arrive at a dollar figure.

${ }^{14}$ The Strategic Petroleum Reserves of fice in the Department of Energy has undertaken extensive analysis of the cost of oil stockpiling.

15 Battelle Pacific Northwest Labortories, An Analysis of Federal Incentives to Stimulate Energy Production, report to the Division of Solar Energy, Energy Research and Development Administration, September 1977. 
Al though current levels of private investment may indicate underinvestment compared to the social benefits associated with nigher levels of investment in solar energy, private market forces by themselves could possibly correct this underinvestment in the future. Therefore, it is necessary to determine anticipated future levels of private investment.

A number of different studies have attempted to project the future market penetration of solar energy systems under baseline conditions (no increased government involvement in solar energy). 16 Market penetration methodologies vary from schematic diffusion analyses, which relate historical patterns of technology diffusion to the cost competitiveness of solar systems (and to a limited extent to other decision factors), to analyses based on consumer surveys. Either approach is difficult to validate, and development of a credible approach to projecting future private investment in solar energy remains a difficult methodological task. ${ }^{17}$

${ }^{16}$ See, for example: (1) Arthur D. Little, Inc., Solar Heating and Cooling of Buildings Report: Part B--Analys is of Market Development, prepared for FEA, September 1977; (2) MITRE Corporation, METREK Division, A System for Projecting the Utilization of Renewable Resources, prepared for ERDA, September 1977; (3) RUP I, Inc., Federal Incentives for Solar Houses: An Assessment of Program Options, prepared for HUD, July 1977; (4) H. Craig Petersen, Impact of Tax Incentives and Auxiliary Fuel Prices on the Utilization Rate of Solar Energy Space Conditioning, Final Report to National. Science Foundation, Utah State University, Logan, Utah, January 1976; (5) Jerome Scott, Solar Water Heating, Economic Feasibility, Capture Potential, and Incentives, Draft Final Report to National Science Foundation, February 1977; (6) Energy and Environmental Analysis, Inc., The Market Oriented Program Planning System Industrial Factor Methods and Results, Draft Report to ERDA, 1977; and (7) SRI International, A Comparative Evaluation of Solar Al ternatives, Supra, note 9. Most of these studies examine market penetration under a variety of solar energy incentive programs.

17 For a discussion of the methodological problems of market penetration models see, D. Schiffel, D. Costello, D. Posner, and R. Witholder, The Market Penetration of Solar Energy: A Model Review Work shop Summary, SERI-16, January 1978. 
The ADL, MITRE, EEA, SRI, and Petersen studies employed similar market penetration methodologies. ${ }^{18} \mathrm{ADL}$ and Petersen consider only solar heating and cooling systems; MITRE and SRI consider all major solar energy technologies. The EEA study examined industrial process heat systems. After cost analysis of the systems considered, these studies related the cost competitiveness of solar technologies to a projected market share. Each study estimated market share assuming that the diffusion of solar systems, when plotted against time, will correspond to the "S"shaped diffusion curve historically experienced by new technologies. The "S"-shaped curve is intended to account for early market resistance in adopting new technologies, a period of market capture by a mature technology, and reduced growth at market saturation.

Several major uncertainties reduce the credibility of this type of analysis. Three significant uncertainties are:

- lack of theoretical or behavioral foundation for the relationship of cost comparisons to descriptive diffusion analysis;

- imprecise definition of the specific markets in which solar technologies would ultimately compete; and - inadequate understanding of actual economic decision criteria used by buyers in various markets.

The RUPI and Scott studies used a different type of methodology to develop estimates of market penetration. Both studies considered only solar space heating and hot water systems for use in homes. In the RUPI study, national and regional market estimates for various incentives were made based on a field survey of 1,500

${ }^{18}$ Supra, note 16. 
homeowners and prospective homebuyers in eight metropolitan areas. This survey was supplemented by interviews with housing market participants (homebuilders and sources of financing), solar equipment dealers and manufacturers, and officials of state and federal agencies. In addition to developing baseline market projections, the study investigated homeowner and homebuyer response to alternative incentives.

The Scott study used data gained from specialized survey instruments to describe demand for solar heated homes. Comparative utility to consumers of increases in first cost, savings in fuel per month, and placement of collector panels on the home was calculated for separate income groups and geographic areas. Demand curve estimates in terms of "probability of purchase" (based on consumer responses) and market penetration (based on builder responses) were developed according to attributes of solar homes including price, increase in first cost over conventional systems, fuel savings, and aesthetics related to position of collector.

Market penetration models based on consumer response data could lead to a better understanding of consumer attitudes toward the purchase of solar energy systems and thereby increase confidence in assessment of the market response to solar energy. But use of consumer response data presents its own set of methodological problems. There is of ten a divergence between hypothesized responses given in a survey and actual decisions on the purchase of a solar system. Also, such studies have difficulty making predictions with changing conditions over time.

Correlation of the results of baseline market penetration estimates with quantitative estinates of the social costs and benefits of alternative levels of solar energy use would help answer the questions of whether underinvestment in solar energy 
technologies exists and whether the pheonomenon is temporary or permanent. Quantification of any current and expected future discrepancy between the level of private investment in solar energy and a more socially optimal level of investment would provide justification for government incentives that might remove this discrepancy. Explicit estimates of the extent of underinvestment would serve as guides for determining the appropriate level of government investment in solar energy incentives. While parts of this information are available in existing literature, more research is needed before satisfactory answers to the questions in this diagnostic element can be provided.

\section{DIAGNOSIS: CAUSATION}

The symptoms element of the informal framework for incentives analysis and evaluation is intended to determine if private markets have underinvested in solar energy. It is the purpose of the causation element to determine why. Al though explicit documentation of underinvestment in solar energy has not been developed (and in fact cannot be developed until the research on solar benefits is done), numerous studies have attempted to determine why solar energy systems are not more widely utilized. 19 Completed research has identified a number of issues which suggest possible causes for assumed underinvestment in solar energy. This review of causation literature is organized around these issues.

In a sense, causes of underinvestment may be considered hierarchical. One cause of underinvestment may be so significant as to make other possible causes insignificant. For example, the

${ }^{19}$ It is important to realize that some completed research on causation may be misdirected. 'Such research indiscriminately asks why investment in solar energy is not greater, without first ascertaining if greater investment is socially desirable. 
high initial cost of solar energy sources may have such a severe impact on the cost competitiveness of solar energy systems as to make the existence of zoning ordinances restricting the use of solar energy systems inconsequential. The relative importance of possible causes of underinvestment has not been definitively determined.

Cost Competitiveness of Solar Energy Systems

Economic analyses have focused on comparing competitive energy sources using a variety of economic analysis techniques (lifecycle costs, levelized energy costs, payback, etc.). These analyses are necessarily based on engineering cost estimates of solar energy systems and a definition of the market in which the technology would compete. They also tend to be based explicitly or implicitly on assumptions to accommodate new technology. The definition of markets, engineering cost estimates for specific applications, and the behavioral assumptions need to be based on improved data.

Several studies have examined the economics of solar heating and cooling. ${ }^{20}$ Each study developed prototypical designs for solar systems in different climates. Based on cost estimates for these prototypes, the costs of the solar system were compared to conventional alternatives on a regional basis. The choice of cost competitiveness criteria has a substantial impact on the analysis

${ }^{20}$ See: (1) Rosalie T. Ruegg, Solar Heating and Cooling of Buildings: Methods of Economic Evaluation, National Bureau of Standards, July 1975; (2) Division of Solar Energy, An Economic Analysis of Solar Water and Space Heating, Energy Re search and Development

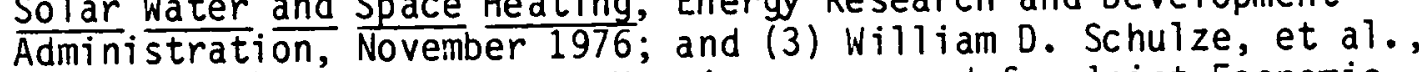
The Economics of Solar Home Heating, prepared for Joint Economic Committee, U.s. Congress, March 1977. Market penetration analyses (Supra, note 16) also evaluate solar economics as a first step. 
results and is a key methodological problem. Several criteria have been used including life-cycle costs, annualized costs, and payback. Studies have also assumed different discount factors or interest rates, system 1 ifetimes, and mortgage terms in making economic comparisons. Al though these analyses provide a general indication of the cost competitiveness of solar systems under assumed parameters, two major questions remain unanswered. First, are the selected parameters and decision rules good approximations of actual decision criteria in the markets in which solar energy will compete? Only limited research has been conducted on actual purchase decision factors. This research has focused principally on the residential sector. ${ }^{21}$ Second, because these studies are usually based on prototypical solar system designs, it is unclear whether the estimated solar system costs are representative.

With regard to solar industrial process heat systems, two major studies have been completed by Battelle Columbus Laboratories and InterTechnology Corporation. 22 The studies developed an extensive energy demand data base for process heat characterized by temperature range and quality of heat required. Examination of this data base allowed preliminary identification of potential markets for solar process heat systems based on system capabilities. These studies undertook conceptual design, cost and performance analyses of several prototypical systems and, based on these analyses, performed preliminary evaluations of the cost competitiveness of solar systems in specific markets. Detailed

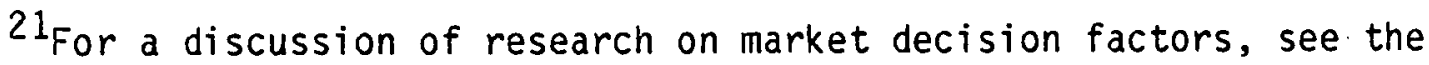
discussion of Demand for Solar Systems below.

22 See: (1) Battelle Columbus Laboratories, Survey of Applications of Solar Thermal Energy Systems to Industrial Process Heat, Report to ERDA, January 1977; and (2) InterTechnology Corporation, Analysis of the Economic Potential of Solar Thermal Energy to Provide Industrial Process Heat, Report to ERDA, February $197 \overline{7}$. 
analyses of the economics of industrial process heat systems in a wide range of markets, however, have not been performed. ${ }^{23}$ Lawrence Livermore Laboratory has developed a standardized economic evaluation methodology for process heat applications, and this methodology is now being applied to each proposed DOE process heat demonstration project. ${ }^{24}$

Several studies have also examined the economics of photovoltaic power systems and preliminarily identified potential markets. A Midwest Research Institute study has determined the system prices necessary for electric utilities to consider such options. 25 Predicted rises in the costs of other fuels, possible reductions in photovoltaic system costs, and incorporation of social benefits into decisionmaking were all considered in the analysis. Social benefits included environmental and health benefits and the reduction of subsidy payments to conventional energy sources that would result from solar energy use. The Electric Power Research Institute has completed a procedure for estimating allowable costs for photovoltaic central station power plants. ${ }^{26}$ In an early mission analysis conducted by Aerospace Corporation, breakeven costs for centralized power plants and onsite residential

${ }^{23}$ The SERI Thermal Conversion Branch is currently undertaking a follow-up on these studies to match solar industrial process. heat systems to promising applications.

24W.C. Dickinson, An Economic Methodology for Solar Assisted Industrial Process Heat Systems, Lawrence Li vermore Laboratory, prepared.for ERDA, June 1977.

${ }^{25}$ See Spectrolab, Inc., Photovoltaic Systems Concept Study, Final Report to ERDA, April 1977. The technoeconomic aspects of this study were done by Midwest Research Institute

26 Electric Power Research Institute, Perspectives on Utility Central Station Photovol taic Applications, EPRI, ER-589-SR, January 1978. 
applications were considered. 27 The analysis points out that current prices do not reflect the real social costs and benefits of energy al ternatives and may cause underinvestment in photovoltaic systems in the future.

Recent research by BDM Corporation and InterTechnology Corporation has analyzed the economic and market potential of photovoltaics in a variety of dispersed markets. BDM has examined both private markets and markets within the Department of Defense. ${ }^{28}$ The ITC study examined private markets for photovoltaics. 29 While not directly addressing the causes of underinvestment in solar energy, these studies lay the groundwork for further analyses. Specification of particular markets in which photovoltaics might compete and of their cost competitiveness in these markets provides essential background information for analyses of both the existence and the causes of underinvestment.

Biomass research has been primarily limited to broad systems studies which characterize biomass technologies, develop cost

27 Aerospace Corporation, Mission Analysis of Photovoltaic Solar Energy Systems, Final Report prepared for NSF, December 1975.

${ }^{28}$ See: (1) BDM Corporation, Photovoltaic Power Systems Market Identification and Analysis, Draft Final Report to DOE, February 1978; and (2) BDM Corporation, Final Report for the Program to Develop a Preliminary Implementation Plan for the Federal Photovol taics Utilization Program, prepared for the U.S. Mobility Equipment Research and Development Command and the Department of Energy, April 1978.

${ }^{29}$ InterTechnology Corporation, Photovoltaic Energy Technology Market Analysis, Report to DOE, January $19 \overline{78 .}$ 
estimates, and preliminarily identify potential markets. 30 Detailed research on the cost competitiveness of biomass utilization is lacking. The extent to which disregard for the social costs and benefits of biomass and competing energy sources may cause underinvestment has not been adequately explored. The same statement applies to solar thermal electric power systems and ocean thermal energy conversion (OTEC) systems. 31

Market Demand for Solar Energy Systems

The market demand for solar energy systems is for the most part considered to be related to the cost competitiveness of solar energy. But individual and organizational perceptions of the risk, utility, and cost associated with alternative energy sources are likely to have major impacts on the demand for solar systems. Even if the market prices of alternative energy sources reflected their real values to society, underinvestment in solar energy (or another energy source) could occur because of attitudes of prospective purchasers.

${ }^{30}$ See, for example: (1) Silviculture Biomass Forms, MITRE Corporation ERDA Contract No. (EC49-8)-208, May 1977; and (2) Systerns Study of Fuels From Sugarcane, Sweet Sorghum, and Sugarbeets, Battelle Columbus Laboratories, ERDA Contract No. W-7405-ENG-92, March 1977.

${ }^{31}$ See, for example: (1) Aerospace Corporation, Solar Thermal Conversion Mission Analysis, prepared for NSF/ $\overline{R A N N}$, January 1974; (2) Honeywe 11 Inc., Solar Pilot Plant, Phase 1, prepared for ERDA, January 1976; (3) Martin Marietta, Central Receiver Solar Thermal Power System, Phase 1, Report to ERDA, Apri 1976; $(4)$ McDonnell Douglas Corporation, Central Receiver Solar Thermal Power System,

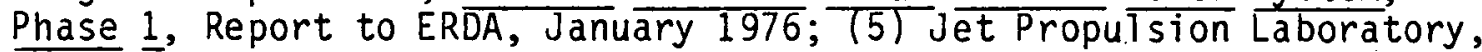
Projection of Distributed Collector Solar Thermal El ectric Power Plant Economics to Years 1940-2000, prepared for DDE, December 1977; (6) TRW Systems Group, Ocean Thermal Energy Conversion Research on an Engineering Evaluation and Test Program, prepared for ERDA, Ju7y 1975; and (7) Lockheed Missiles and Space Co., Potential of Accelerating Commercialization of Ocean Thermal Energy Conversion, prepared for ERDA, October 1975 . 
A few studies have explored consumer attitudes toward residential solar heating and hot water systems. ${ }^{32}$ some studies have required 1 arge numbers of respondents to choose between different combinations of solar and conventional heating systems. ${ }^{33}$ The data from these surveys, in addition to being used to estimate demand for solar systems (see the discussion of symptoms), have been used to highlight several consumer concerns, including style of home, risk of system failure, comfort, and lack of information.

The Real Estate Research Corporation, under contract to HUD, is engaged in an extensive effort to analyze market response to residential projects awarded grants in the HUD Solar Heating and Cooling Demonstration Program. ${ }^{34}$ This study is designed to compare the attitudes of purchasers of solar demonstrations to those who purchased conventional housing. Similarly, the attitudes of builders participating in the prograin are to be compared to competitive builders with no experience in solar energy construction. The overall objective of this research is to describe the important factors affecting market response to solar energy homes. This research will continue for the duration of the

${ }^{32}$ See, for example: (1) Jerome Scott, Solar Water Heating, Economic Feasibility, Capture Potential and Incentives, Supra, note 16; (2) RUPI, Inc., Federal Incentives, Supra, note 16; (3) Decisions and Designs, Inc., Attitudes and Beliefs of Consumers and and Supporting Institutions About Solar Heating in the Home, prepared for FEA, 1977 (Draft); and (4) Nationa Demographics Lt d., Attitudes and Behavior Related to Energy Conservation, Denver, Colorado, Report to ERDA, October 1977 .

${ }^{33}$ The Scott and RUPI studies are good examples of studies in this category, Supra, note 16.

${ }^{34}$ For a description of this ongoing analysis, See Real Estate Research Corporation, HUD Residential Solar Heating and Cooling Demonstration Program Marketing and Marketing Acceptance Plan, prepared for the Department of Housing and Urban Development, August 1977. 
demonstration program and should advance understanding of possible causes for underinvestment in solar energy in the residential sector.

Al though some examination of attitudinal factors affecting solar energy purchase decisions has been undertaken for the residential sector, there is a question concerning the extent to which results can be generalized. Small samples, in some cases not statistically valid, make it difficult to draw conclusions concerning how attitudes affect underinvestment in solar energy technologies. Attitudinal research of this nature in the commercial, industrial, and institutional buildings sectors is largely nonexistent. Examination of attitudinal factors in other markets in which solar process heat, wind, photovoltaics, and other solar electric technologies could compete (e.g., the utility sector) has also been extremely limited.

\section{Development of Industry Infrastructure}

Given the small number of applications for which solar energy systems are currentiy cost-competitive, it is understandabie that there is not a well-developed industrial capability to manufacture, distribute, sell, install, and service them. The question arises whether this underdeveloped infrastructure will itself be an impediment to solar penetration once widespread costcompetitiveness is achieved, and thus a cause of (rather than only a symptom) underinvestment in solar technologies. To answer this question, the operations of the industries which are likely to supply solar equipment must be understood.

Schoen and Hirshberg have described the historical patterns of industry resistance to innovations in the building industry. The fragmentation and horizontal stratification of the building industry itself tend to slow the diffusion of new products into 
the industry. In some instances (e.g., the introduction of PVC plastic pipe), the industry has exhibited stiff resistance to the introduction of new products that clearly offer cost advantages. In this case, the plumbers union and the copper industry used their influence to delay change. One can reasonably expect that the integration of solar heating and cooling systems into the building industry will experience similar resistance and delays. ${ }^{35}$

A study by InterTechnology Corporation provides a schematic description of how the solar heating and cooling supply industry is likely to develop. 36 The hypothesis of the study was that the industry will evolve along the same lines as the industry which supplies heating, ventilating, and air conditioning equipment. Al though, no empirical evidence was offered to support this hypothesis, if true it would indicate that HVAC supply and distribution mechanisms could be adapted to supply. and distribute solar heating and cooling equipment.

The experience of the solar hot water demonstration program supported by New England Electric is a dramatic illustration of how 1 ack of a developed infrastructure can impair development of the solar industry. The program provided for the purchase and installation of 100 residential solar water heaters of various types by numerous installation contractors. In the first year of operation, a substantial number of these systems failed to operate

35 See: (1) R. A. Schoen, S. Hirshberg, and J. M. Weingart, New Energy Technologies for Ruildings: A. Report to the Energy Policy Project of the Ford Foundation, (Cambridge, Mass: Ballinger, 1975); and (2) A. S. Hirshberg, "Public Policy for Solar Heating and Cooling," Bulletin of the Atomic Scientists, Vol. 32, No. 8, p. 39, October 1976.

${ }^{36}$ InterTechnology Corporation, Industry-Market Infrastructure Analysis, Report to the Federal Energy Administration, June 1976. 
effectively because of improper installation. ${ }^{37}$ AIA Research Corporation, using a survey of architects and engineers to describe key problems confronting the solar industry, also found that lack of basic solar design and construction skills were perceived as a key problem confronting the industry. ${ }^{38}$

Existing literature provides only a sketch of how the industry infrastructure might develop for the delivery of solar heating and cooling systems. Existing research suggests that the operations of the industry, even given a cost-competitive technology, may constrain solar energy investments. The importance of this constraint needs to be determined. Further research is needed to describe the motivations and behavior of those companies that are likely to play a role in the solar heating and cooling industry, and the industries that are to supply other solar energy technologies, so that constraints on the development of industrial capabilities can be understood.

\section{Financing Constraints}

Even if a solar energy system is recognized as cheaper than a conventional system on a life-cycle cost basis, it is possible that a consumer will not buy the solar system because of cash (income) constraint (i.e., an inability to fund the investment in energy savings). Typically, in such situations, a financial institution would offer a loan to the consumer, effectively eliminating the constraint. Homeownership, for example, would be beyond the means of most of the population without the availability of long-term mortgages. It is not certain that such

37. Under contract to New England El ectric, Arthur D. Little, Inc., has documented the experience of this program.

${ }^{38}$ AIA Research Corporation, Early Use of Solar Energy in Buildings, Report to NSF, August 1976. 
arrangements will be available for the purchase of solar energy systems. In this situation, the cause of underinvestment is the unavailability of conventional financing to relax the income constraint.

RUPI, Inc. has examined in detail the potential constraints to obtaining financing for residential solar energy systems. 39 Survey techniques were used to measure mortgage market receptivity to solar financing. Structured in-depth interviews were conducted with residential mortgage loan officers from New England financial institutions (commercial banks, insurance companies, mutual savings banks, co-operative banks, and savings and loan institutions). There were 150 supplementary interviews with a variety of national sources to secure information on mortgage market trends, regulatory activities, and general mortgage lending practices. The study concluded that the uncertain value of solar energy systems on the resale market was one of the primary sources of lender reluctance to provide financing for solar energy systems. Traditional mortgage eligibility criteria do not account for energy costs, and the reduction in the financable fraction of total home purchase costs may force solar home buyers to purchase a home with less square footage and amenities than they would normaliy choose. A more likely outcome in this situation is that a home buyer would forego solar. Financing of retrofit systems is likely to be provided through a home improvement loan which is usually granted on the basis of the applicant's financial status. An evaluation of the improvement is not a lending factor. RUPI describes a number of incentives that might eliminate any external constraint on solar energy use by the lending process.

${ }^{39}$ D. Barret, P. Epstein, and C. Haar, Financing the Solar Home: Understanding and Improving Mortgage Market Receptivity to Energy Generation and Housing Innovation, Re gionaT and Urban Planning Implementation, Inc., Report to NSF, June 1976. 
Standards, Codes, and Legal Constraints

Another external constraint potentially causing underinvestment in solar energy is the existence of standards and building and zoning codes which may inadvertently restrict solar energy use. Solar specific codes and standards may be desirable to avoid potentially costly delays associated with obtaining code approval for solar systems and to assure purchasers that solar equipment will perform adequately. Early studies suggested that the lack of codes and standards specific to solar systems could act as a barrier to the commercialization of solar heating and cooling. ${ }^{40}$ This conclusion, and the provisions for code and standard development mandated in the Solar Heating and Cooling Demonstration Act of 1974 (PL 93-409), have led to an aggressive program to develop and implement codes, standards, test, and certification procedures and to encourage provision of warranties on solar heating and cooling equipment. The prescription section below will provide a discussion of responses to the potential constraint posed by codes and standards. Several studies have examined the possible constraint posed by the lack of guaranteed access to solar radiation. Two studies suggest that sun rights have yet to pose a problem to the installation of solar systems. ${ }^{41}$ However, as solar utilization spreads, particularly in high density areas, there is some concern that sun rights may become a problem. Proposals for adoption of state and local solar zoning ordinances and solar

${ }^{40}$ See, for example: (1) General Electric Company, Survey to Define Impact of Statewide Building Codes on Solar HVAC Systems, prepared for ERDA, 1976; (2) AIA Research Corp., Early Use of Solar Energy in Buildings, Supra, note 38; and (3) schoen, et a1., New Energy Technologies for Buildings, Supra, note 35, pp. 171-200. 41

See: (1) AIA Research Corporation, Early Use of Solar Energy in Buildings, Supra, note 38 and (2) Richard L. Robbins, "Law and Solar Energy Systems: Legal Impediments to Solar Energy Systems," Solar Energy Vol. 19, No. 5, 1976, pp. 371-379. 
easements have been advanced. 42 However, there is no consensus on the importance of such a policy action or on the best approach to resolve this potential problem.

Louis Mayo has evaluated the potential for successful implementation of wind energy conversion systems (WECS) given the current legal and institutional structure. ${ }^{43}$ The study developed "strawman" project configurations specifying the technical, social, and economic context of wind energy. Then, the legal and institutional constraints likely to arise from each WECS configuration were discussed. The legal problems posed by offshore WECS configurations were also addressed. The report concluded with recommendations for legal and institutional changes needed to facilitate WECS utilization. ${ }^{44}$

Washom and Nilles have identified legal and institutional constraints to the utilization of OTEC systems. 45 The extent to which these problems can currently be considered a cause of underinvestment in OTEC is questionable given the technical and economic status of the technology.

${ }^{42}$ See: (1) American Bar Foundation, Legal Is sues Related to the Use of Solar Energy Systems, August 1976; (2) Environmental Law Institute, SoTar Energy and Land Use in Colorado, Report to NSF, April 1976; and (3) Robbins, Supra, note $\overline{42}$.

${ }^{43}$ Louis H. Mayo, Legal-Institutional Implications of Wind Energy Conversion Systems (WECS), Report to NSF, September 197.7.

${ }^{44}$ For another report on wind energy, see: R. F. Taubenfeld and H.J: Taubenfeld, Barriers to the Use of Wind Energy Machines: The Present Legal/Regulatory Re gime and a Preliminary Assessment of Some Legal/Pol itical/Societal Problems, Report to NSF, July 1976. This study provides a less detailed description of potential WECS barriers.

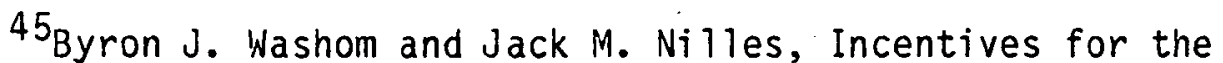
Commercialization of Ocean Thermal Energy Conversion Technology (OTEC), University of Southern California, Report to NSF, January 1977 , I1-I 20. 
Interface With Existing Energy Supply and Distribution Network

Another external constraint that might cause underinvestment in solar energy systems is the interface with existing energy supply and distribution mechanisms. Institutional procedures for selecting energy supply technologies, requirements for backup energy sources, and rate structures could potentially make it difficult for solar energy systems to make a significant energy contribution, even though a higher level of utilization might be socially desirable. ${ }^{46}$

Some research has focused on the interaction between solar heating systems and utility rate structures. Solar buildings with electric backup systems require power from utilities at levels and tines not yet clearly identified. Utility rate structures in turn determine the value to consumers of displaced energy. Feldman and Anderson have constructed a model to calculate costs to utilities, consumers, and the national economy for any solar building/utility combination. 47 A simulation model was used which incorporated building performance, historical weather conditions, utility characteristics, and solar construction costs. A subsequent study by Feldman and Anderson allows adjustments in building design to

46 It should be noted that the reverse--overinvestment in solar energy--could occur because of the structure of current electric rates. There is some evidence to suggest that current rates may subsidize solar energy systems, in that the full demand charges which cover the costs the utility incurs to maintain generating capacity may not be paid, due to the lower total energy consumption of the solar home. Existing rates in most cases are based on the average electricity use of a home in a given rate class, and demand charges are spread throughout the rate. To the extent that solar energy homes present similar peak demand profiles but consume significantly less energy, the solar customer may be subsidized by the utility.

47 Steven Feldman and Bruce Anderson, Utility Pricing and Solar Energy Design, C1 ark University, Report to NSF, September 1976. 
optimize costs with respect to utility rates. ${ }^{48}$ These studies indicated that current rate structures applied to some solar energy designs do not adequately reflect the cost of service. The exact interactions between solar systems and the utilities, however, are very specific to climate, utility, generation mix and load profiles, and solar system design. Other studies have considered the effects of residential solar space conditioning on utilities. ${ }^{49}$ Utilities and solar energy proponents are concerned about the interaction of various types of dispersed and centralized solar technologies with utility generation mixes. Solar proponents are concerned about the disincentive effects of high, perhaps discriminatory, rates for backup power to solar heated homes. Utilities are concerned about effects on load management, capital facility planning, and revenue effects of widespread decentralized solar use. Interest in the interface of solar technologies has stimulated a wide variety of utilitysponsored solar experiments, primarily in solar heating and cooling, ${ }^{50}$ and several conferences on solar-utility interface. ${ }^{51}$

${ }^{48}$ Steven Feldman and Bruce Anderson. The Impact of Active and Passive Solar Building Design on Utility Peak Loads, Interim Report to ERDA, September 1977.

${ }^{49}$ See, for example: (1) Harold Lorsch, Implications of Residential Space Conditioning on Electric Utilities, Franklin Institute Report to NSF, September 1976 and (2) Energy Rate Initiatives: Study of the Interface Between Solar and Wind Energy Systems and Electric Utilities, Federal Energy Administration, March 1977.

${ }^{50}$ See, Louise 0. Cleary, Electric Utility Solar Energy Activities 1976 Survey, El ectric Power Research Institute (ER-321-sr), January 1977 and Electric Utility Solar Energy Activities - 1977 Survey, Electric Power Research Institute (ER-649-sr), 1978. The interface between gas utilities and solar systems has been examined in a variety of projects, most significantly, the Solar Assisted Gas Energy (SAGE) experiment sponsored by NSF and and the Southern California Gas Co.

${ }^{51}$ Several conferences have considered this subject. For example: (1) "Small Power Systems Solar Electric Workshop," October 10-12, 1977, Aspen, Colo., sponsored by DOE and NASA and (2) "The Role of Utility Companies in Solar Energy," November 6-8, 1977, Washington, D.C., sponsored by the Institute of Gas Technology and Gorham Internationa?, Inc. 
Interest has not been limited to the examination of utility interactions with solar heating and cooling systems. The Aerospace Corporation and the MIT Energy Laboratory have examined the interactions of various configurations of photovoltaic power systems and electric utilities. ${ }^{52}$. This work is in a preliminary stage with final results on photovoltaic power systems and utility interactions still in the future.

Legal and institutional resistance to changes in the scale of utility power generation was identified as a major problem in a study by the Environmental Law Foundation. 53 This study drew on interviews with federal, state, and local government agency personnel, as well as private companies involved in solar development. Examination of statutory and case law revealed potential constraints to solar energy use evolving from utilities' rights as regulated monopolies. Questions concerning who should own, operate, and maintain dispersed solar energy systems were al so raised. It has been suggested that utilities could serve as the owner, lessor, or service company for dispersed systems, offering their access to capital and established billing and service networks to accelerate solar energy implementation. Public interest groups have insisted that this type of utility involvement is ill-advised. 54

52 For a summary of this work, see Proceedings of the Photovoltaic Systems and Applications Workshop, sponsored by DOE, coordinated by Sandia Laboratories, Reston, Va., December 13-15, 1977.

53 Karin $\mathrm{H}$. Hillhouse, Legal and Institutional Perspectives on Solar Energy in Colorado: A Case Study of Land Use and Energy Decision-Making, Environmental Law Foundation, report to the National Science Foundation, November 1977.

${ }^{54}$ For a discussion of the advantages and disadvantages of utility involvement in the solar industry, see "The Case Against Private Utility Involvement in Solar/Insulation Programs," Solar Age, January 1978, pp. 23-27. 


\section{PRESCRIPTION}

Given adequate diagnosis of underinvestment and an understanding of its causes, the next step is the selection of incentives that would lead to a more socially optimal level of solar energy utilization. Incentives selected for implementation must be effective in increasing solar energy investment, as well as socially efficient in that the social benefits of the incentives program exceed its social costs.

To select solar incentives effectively, it is first necessary to know what incentive tools are available to the government. Recent studies have examined a wide variety of possible incentives for encouraging the use of solar heating and cooling systems in buildings. ${ }^{55}$ An example of a study examining a large number of incentives is the Solar Heating and Cooling of Buildings Commercialization Report, prepared for FEA by Midwest Research Institute and Arthur D. Little, Inc. Direct incentives examined include grants, income tax credits and deductions, investment tax credits, accelerated depreciation, and low interest loans. Indirect incentives examined were programs for government buildings, demonstrations, consumer financial education, building codes and certification, utility rates, utility leasing or ownership, and government insurance. A preliminary determination was made of which incentives could be effective in reducing potential constraints to widespread utilization of solar heating and cooling systems.

${ }^{55}$ Supra, note 16 . 
It is important to note that studies which have examined a large number of incentives typically define indirect incentive options in general terms. For example, a consumer education program may be described conceptually, without specifying objectives and operations of the program. Direct incentives are usually defined more concretely, offering a range of parameters which could be used in the incentive. The administrative details of direct incentives, however, are usually not described. Typically, studies recommend or conceptually investigate al ternative subsidies or incentives. Rarely do these studies estimate social benefits and costs of incentives, make good quantitative estimates of the response to the incentives, or investigate their possible operation in detail.

An important consideration in the selection of solar energy incentives is the status of the technology. In addition to the range of commercialization incentives mentioned above, support of research and development or the construction of experimental pilot plants or public demonstrations are major incentive options available to the government. Since the inception of federal solar - energy programs, the bulk of funds has been applied to research and development (with the exception of the demonstration program for solar heating and cooling). Only recently has consideration been given to the application of commercialization incentives to accelerate private utilization of solar energy systems. The choice between government incentives for commercialization versus support of research and development has been a subject of considerable debate within the solar energy program. ${ }^{56}$ A clear

56 For a discussion of this controversy with regard to solar heating and cooling, see Hearings Before the Select Committee on Small Business, U. S. Senate, "Solar Energy: How Much? How Much from Small Business? How Soon? Why Not More? Why Not Sooner?" May 13-14, 1975. 
understanding of where incentives should be directed for the different solar technologies has not been developed. The current concern over the efficiency of large-scale federal subsidies for purchasing photovoltaics is an illustration of this void. When does a shift to a "demand pull" market incentive become appropriate? Are government funds best invested in increased support for research and development? A recently completed SERI research project addressed this issue. 57 Research on the application of government incentives to other new technologies is particularly relevant in determining what incentives are appropriate at different stages of technical development. 58 There is a need to apply the results of this research to the selection of solar energy incentives.

As part of the prescriptive element, it is necessary to examine closely the private decision processes that resuit in underinvestment, to determine what is required to alter these decisions to bring about a higher level of investment in solar energy. In a study of incentives for the residential use of solar energy, RUPI, Inc., used a consumer survey to determine the key factors in a decision to purchase a solar energy system. 59 As part of this survey, an attempt was made to estinate the "threshold" incentive level needed to encourage purchase. Consumers were asked to specify what incentive would be required

${ }^{57}$ SERI, Photovoltaic Venture Analysis, Final Report, SERI/TR$052-040$, JuTy 1978.

${ }^{58}$ There is a significant body of literature on federal incentives for new technologies. See, for example: (1) MIT Energy Laboratory, Government Support for the Commercialization of New Energy Technologies, November $\overline{19} \overline{6 ;}$ (2) Sumner Meyers, et $\overline{\text { a1. }}$, Federal Incentives for Innovation, Denver Research Institute, January 1976; and (3) "Government-Sponsored Demonstrations of New. Demonstrations of Technologies," Science, 196, May 27, 1977.

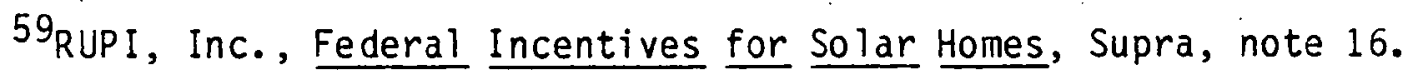


to alter their normal decision habits. This information is critical to defining an incentive which will elicit some market response. Environmental Future conducted a study of the transmittal of information within the building industry. 60 The study analyzed existing mechanisms for the provision of building product specifications, the roles that these specifications play in the introduction of new products into the building industry, and the function of trade associations in the transmittal of information. The study concluded that the poor availability of information to the industry will be a constraint to the rapid adoption of solar energy and energy conservation techniques. EFI proposed the establishment of a group of energy implementation centers that would accelerate the flow of pertinent literature into existing information channels within the industry. This type of analysis, examining how the industry operates and then developing a program to complement these operations, is an example of what is required to develop effective incentives.

The federal initiative to accelerate the implementation of codes and standards for solar heating and cooling systems is another example of a program that evolved from a diagnosis of a problem, subsequent understanding of its causes, and identification of existing mechanisms that could be exploited to overcome the problem. Interim performance criteria for heating and cooling systems for both residential ${ }^{61}$ and commercial ${ }^{62}$ systems as well as

60 Al an Hirshberg, Energy Implementation Centers: A Means of Speeding the Use of Solar Energy and Other Energy Conserving Technologies, Environmental Future, Inc., Report to NSF, December 1976.

$61_{\text {National Bureau of Standards, Interim Performance Criteria for }}$ Solar Heating and Combined Heating/Cooling Systems in Dwell ings, prepared for HUD, washington, D.C., January 1975.

62 National Bureau of Standards, Interim Performance Criteria for Commercial Solar Heating and Combined Heating/Cooling Systems and Facinities, prepared for ERDA, February 1976. 
Intermediate Minimum Property Standards 63 for heating and not water systems have been developed. Test procedures have also been developed for rating performance of solar collectors and thermal storage devices. 64 These criteria and test procedures are the basis of industry consensus standards adopted by SEIA, ASHRAE, ANSI, and other relevant organizations. Minimum Property Standards are now used as guidelines for FHA and VA mortgages and for the HUD Demonstration Program and will likely be used for any federal solar tax incentives. These standards are also typically used as guidelines in private lending decisions.

Studies under the direction of NBS are beginning to construct implementation plans for a wider system of solar codes and standards. One aspect of this effort is to develop an implementation plan for test and certification procedures for solar equipment. The overall objective is to assure consumer protection. Another aspect is directed at developing model code 1 anguage and implementation strategies to accelerate the diffusion of solar code provisions into local building codes.

Once an incentive has been defined which appears promising in alleviating a cause of underinvestment, it is necessary to estimate the short- and long-term impacts of the incentive. For direct incentives, it is a simple matter to calculate the impact of the incentive on system costs. Ruegg has examined the impact of various tax and loan incentives on the life-cycle costs of

$63_{\text {National Bureau of Standards, Intermediate Minimum Property }}$ Standards for Solar Heating and Domestic Hot Water Systems, prepared for HUD, JuTy 1977.

64James Hi 11, et al., Development of Proposed Standards for Testing Solar Collectors and Thermal Storage Devices, National Bureau of Standards Technical Note 899 , U.S. Department of Commerce, February 1976. 
solar heating and cooling systems. ${ }^{65}$ A similar analysis has been conducted for industrial process heat systems. ${ }^{66}$ By itself, the impact of an incentive on system cost does not provide an estimate of private response, nor does it address the fundamental social question of whether the benefits justify the costs. An explanation of the adoption decision, to which incentives are just one contributing factor, is necessary to the pursuit of both questions. Market penetration models are a place to begin.

As discussed above, a number of market penetration models have been used to project future private market response to solar energy. ${ }^{67}$ The methodological limitations of these models have already been discussed. Though improvements in methodology are needed, market penetration models remain one of the only tools available for estimating future market responses. A basic application of market penetration models has been to estimate the response to solar energy incentives. This is done by first projecting future market penetration under baseline conditions, and subsequently with the incentive in effect. The differential penetration is assumed to be the effect of the incentive. For the most part, market penetration models can analyze only direct incentives. Typically, the incentive is entered into the model as a reduced system cost which is predicted to correspond to a higher level of penetration. ${ }^{68}$ Because market penetration models do not address the adoption decision explicitly, analysis of the

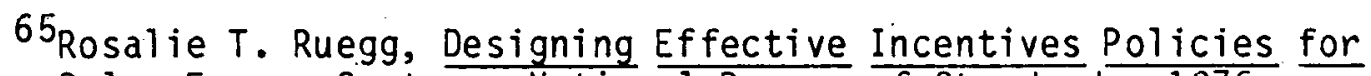
Solar Energy Systems, National Bureau of Standards, 1976.

${ }^{66}$ Supra, note 24.

${ }^{67}$ Supra, note 16 .

68 Models based on consumer response data actually ask consumers if their decision whether or not to purchase a solar system would be altered by the incentive. 
potential impacts of indirect incentives has been extremely 1 imited, and methodologies for this analysis are lacking.

Another critical aspect in estimating the impact of an incentive is predicting the response of the supply industry. Market penetration models usually assume that the increased demand for solar energy systems resulting from an incentive will lead to lower system prices because of improved efficiency in supply capabilities. This assumption is based on what is commonly referred to as the learning or experience curve. Lack of clear documentation of the sources of reductions in cost due to learning and uncertainty regarding industry's response to incentives raise major questions about the validity of these projections. ${ }^{69}$ Yet in most market penetration estimates of incentive effectiveness, the hypothesized price reductions due to increased demand lead to even greater demand, lower prices again, and so on. Generally, this approach projects, for a given reduction in system price, the same self-reinforcing sequence of supply and demand responses, no matter what the source of that price reduction.

Two studies have examined incentives which are explicitly intended to improve industrial supply capabilities, leading to reduced systems costs and a higher level of penetration. MITRE Corporation analyzed federal purchase of solar. heating and cooling systems, 70 and BDM Corporation analyzed federal purchase of photovoltaics. 71 The stated purpose of these programs is to provide guaranteed markets for solar systems and thereby

${ }^{69}$ Supra, note 57.

${ }^{70}$ Solar Energy Government Buildings Program Policy and Implementation Plan, Prepared for FEA by the MITRE Corporation, January 1977.

$71_{\text {Preliminary Analysis of an Option for the Federal Photovoltaic }}$ Utilization Program, prepared by BDM Corporation for FEA, JuTy 1977. 
facilitate industry capitalization. While these studies consider the costs and benefits associated with the proposed program, detailed analyses of the effects on long-term industrial supply capabilities, in terms of capacity or production cost, were not undertaken.

The final requirement of the prescriptive element is to construct an overall program for solar energy incentives. Once a set of candidate solar incentives and technologies to which they are to be applied has been developed, it is necessary to select incentives and technologies for implementation. In Chapter II it was argued that the incentives selected should be justified in terms of their social benefits exceeding their social costs. Bezdek ${ }^{72}$ has proposed the following 1 ist of additional measures for determining whether or not to implement an incentive:

\footnotetext{
- income distribution effects;

- multiplier effects on investment;

- administrative efficiency;

- operating costs above administration;

- solar investment increase;

- increase in market penetration;

- duration of effect;

- side effects on the economy; and

- miscellaneous social effects.
}

The relative importance of these criteria was not evaluated.

\footnotetext{
${ }^{72}$ Roger Bezdek, et al., Analysis of Policy Options for Accelerating Commercialization of Solar Heating and Cooling Systems, April 1977, pp. 41-45.
} 
While there seems to be consensus that the combination of incentives offering the greatest social benefits for a given cost is most desirable, specific procedures to arrive at this set of incentives have not been developed. SRI International has. correlated a market penetration analysis with the social benefits associated with use of each solar energy technology. ${ }^{73}$ This type of correlation is an essential component in selecting incentives. The administrative feasibility and cost of an incentive must also be considered. The extent to which equity should be a factor in incentive selection is subject to question. A specific methodology for developing an integrated federal solar energy incentives program is needed. Any rationally designed incentives package must be developed within the guidelines of the extent of underinvestment diagnosed, the expected effectiveness of the incentives package in correcting that underinvestment, and the social efficiency requirement that the incentives package makes a net contribution to social welfare.

\section{E. EVALUATION}

After an incentive has been implemented, it is important to evaluate its effectiveness. Much valuable information can be gained froin examining actual experience with incentives. Ideally, evaluations of incentives would use actual data on purchase and use of solar systems to verify attitudinal data, to predict consumer behavior, to test theories, and to aid future preimplementation analyses of how consumers would respond if a particular incentive were enacted. However, with the exception of the national heating and cooling demonstration program and solar energy $R \& D$ support programs, incentives at the state level are the

${ }^{73}$ SRI International, A Comparative Evaluation of Solar Al ternatives, Supra, note 9. 
only solar incentives which have been in effect for more than one year. Hence, evaluation research on federal solar programs has been necessarily limited.

Various types of solar incentives have been enacted by numerous states. These incentives include property tax exemptions, income tax deductions and credits, solar easements and zoning ordinances, and establishment of standards and certification procedures. While it is possible that a few states have collected data on the use of solar incentives, no comprehensive analysis of the effectiveness of state incentives offered has been conducted.

As for national incentives, data on the solar heating and cooling demonstration program have been collected since the program was first initiated in 1975. For the residential program, HUD has contracted with the Real Estate Research Corporation to monitor program activities. 74 Most analyses of the demonstration program conducted to date have focused on identification of problems associated with projects in the program. No analyses of the overall impact of the demonstration program on the solar industry or possible consumers have been completed. The results of the RERC study should provide information of this type.

Some evaluation of solar research and development programs has been conducted. Most of these are undertaken for program management purposes and do not try to assess the reduction in underinvestment that may have occurred, or the social benefits and costs generated. For example, in the photovoltaics program, the performance of the industry measured in terms of cost and volume of output has been compared to DOE program goals, to monitor the

${ }^{74}$ Real Estate Research Corporation, Plan for Non-Technical Survey Research Activities for the HUD Residential Solar Heating and Cooling Demonstration Program, prepared for HUD, January $1 \overline{977 .}$ 
impact of the national program. While similar types of evaluative efforts have been undertaken in various parts of the solar program, no comprehensive effort to monitor the overall impacts of the national research and development program has yet been attempted. Measuring the effectiveness of R\&D support as an incentive is particularly difficult compared to measuring the impact of other incentives.

Several direct incentives for solar energy have been initiated recently or are expected to be initiated in the National Energy Act (NEA). The solar hot water initiative for residential and commercial buildings is currently being implemented. ${ }^{75}$ The NEA is expected to contain several incentives for solar space conditioning systems and wind systems, including a residential tax credit, a business investment tax credit, and a federal buildings program. Several opportunities for collecting and evaluating data on incentives should be available after these incentives are in effect.

Considerable uncertainty surrounds the feasibility and scope of future incentive evaluation activities. An understanding of what information is useful and can be obtained from past and future incentives programs needs to be developed. Techniques for analysis of information derived from evaluative activities also need to be developed.

${ }^{75}$ The hot water initiative is an extension of the federal demonstration program. The residential portion of the program calls for the subsidization of approximately 11,000 hot water units at an average level of $\$ 400 /$ system in 11 states with high electric heating costs. The commercial initiative is restricted to hotels and motels. 


\section{F. MAJOR REQUIREMENTS FOR FURTHER RESEARCH}

The analytical framework contained in Chapter II defined information needed to determine if underinvestment in solar technologies has occurred and to develop effective and efficient incentives to correct this underinvestment, if such an objective is desirable from a policy point-of-view given other demands for scarce government funds. From the review of the available research, it can be observed:

- It is not currently possible to define the socially optimal level of investment in solar technologies because neither the social benefits to be gained from solar utilization nor the costs necessary to achieve solar utilization have been adequately defined or analyzed.

- It is not currently possible to identify the best incentives to modify private investment decisions with respect to invention, development, manufacture, or adoption of solar energy devices and systems. This inability is caused by insufficient present understanding of:

- the decision and behavioral processes and criterla governing private responses to solar technologies generally and to particular applications of selected solar products;

- the lessons for solar incentives of previous experiences with government incentives, especially in the areas of energy $R \& D$ and commercialization of new technologies; 
- the efficiency and efficacy of solar incentives proposed or already implemented.

- It is not currently possible to identify those solar technologies which will satisfy a widely acceptable set of social, economic, and technical criteria for substantial governmental support at particular stages in the technology product development process. Policymakers and solar decisionmakers have not articulated such criteria fully or explicitly. With those criteria it is possible to develop a rational policy for solar and other energy technologies. Without those criteria it is difficult to assess the effectiveness and efficiency of incentives options.

- It is not currently possible to specify the procedures by which society will select and implement alternative energy options. The research literature has not systematically addressed the institutional questions which seem to underlie the changing thrust of federal programs and of public attitudes toward energy futures. These observations suggest the existence of substantial gaps in currently available research. These gaps must be filled before decisionmaking on solar energy incentives can be improved.

In addition to the need to fill specific research gaps, this 1 iterature review has uncovered the need for a coordinated research prugrall that w111 lay the foundation for the strategic planning required to develop an integrated solar energy incentives strategy. Too often in the past, research on solar policy questions has been conducted on a fragmented basis with little effort devoted to understanding how individual research projects are related. A large portion of completed research has been 
oriented toward providing answers to immediate policy questions. The result of this fragmentation and emphasis on isolated policy questions is that the capabilities to address the implications of major solar policy decisions are lacking. A principal objective of the research agenda described in the next chapter is to place individual research progress in a structure that will allow progress to be made on the development of a framework directed at evolving a well-planned solar incentives strategy. 


\section{RESEARCH AGENDA}

This chapter describes a series of research areas to yield information which can improve government efforts to specify, design, and justify incentives for solar energy technologies. The research agenda will help to eliminate the gaps in knowledge identified in Chapters II and III. The results of completed studies, where relevant, will be the starting point for the proposed research. However, much new research is needed before the gaps identified can be adequately filled.

\section{A. A NOTE ON RESEARCH PLANNING}

It is not intended that this research program be completed in the short term. Many of the issues and information gaps identified earlier in this report have confronted energy policymakers for a number of years. Despite this fact, the necessary research on energy policy issues cutting across alternative technologies has not been conducted. This situation partly results from agency emphasis on solving short-term political and budget problems, while research on these particular issues and information gaps is a longer term effort. In part, this situation is due to changing emphasis in the federal energy establishment--from an historical emphasis on creating technical energy options for society to a new emphasis on how society should select among and implement those options. In the solar area, research on implementation and utilization incentives was understandably limited until there were reasonably cost-effective, reliable solar technologies available for (or foreseeable in) the marketplace. 
Despite the change in relative emphasis of federal energy efforts and despite the greater availability of solar products, supporting research on economic, social, and value issues with respect to solar energy cannot be quickly performed. First, after some point acceleration of individual research projects can be achieved only at the cost of sacrifices in quality. Second, one or two research projects on a topic are seldom sufficiently persuasive. A volume of credible research must be conducted and related to existing bodies of knowledge to provide confidence in the accumulated research findings. Thus, the research agenda described below should not be considered a short-term agenda, al though some parts of it should yield useful short-term results. The research agenda is simply a structured approach to incentives issues that, if followed, will enable more effective management of research progress in this area.

The results of this research should provide decisionmakers with four different and necessary inputs: (1) a systematic approach or model by which decisions required for each technology can derive from more timely and more relevant information; (2) an integrative approach or model providing an analytical basis for allocating resources among a number of solar energy technology options; (3) an assessment of the value to society of alternative incentive options; and (4) a description of the most efficacious design and administration of incentive options.

Ideally energy policymakers and program managers should have an overall strategy for making choices among technological options experiencing underinvestment in the private sector. The proposed research will establish a strategy for making better decisions about the level of support and the kind of support each technology requires as systems improve and become more likely candidates for private investment in commercial markets. This of course is an essential input for designing appropriate incentives. 
In addition, the research agenda and the information it develops should strengthen the agency decisionmaking process against the vagaries of social and political issues and pressures. At the same time the research agenda can incorporate these considerations in the design and objectives of specific research tasks.

\section{B. SETTING RESEARCH PRIORITIES}

Research, like other activities, consumes scarce resources (time, money, and talent) in the expectation that something of value will be produced. Hence, research priorities must be established by considering research costs and the relative value of the expected research outputs.

The value of the research outputs is determined by how well the research informs and improves public decisionmaking. Thus, research priorities can be established by considering the decisions that must be made, when the decisions must be made, the current availability and quality of information to support the decision, and the improvement in decision-relevant information that research might provide. To be most valuable, research should be based on decisions that will have to be made in the future and the analytical information that will be needed to support those decisions. By articulating future decision requirements and information needs, it becomes possible to identify research priorities as well as to sketch the strategic, future-oriented framework within which current decisions must be made.

The research agenda proposed below organizes research into the following broad categories: 
- Specify and estimate any present underinvestment in solar technologies and the social benefits and costs to be expected from a greater utilization of solar energy. and compare these with conventional and advanced energy technologies to determine the incentives that would be necessary to overcome underinvestment;

- Establish a strategic framework for defining necessary incentives research on each solar technology;

- Examine results of earlier product development efforts to identify critical factors required in an incentive and explain and model the decision processes governing private investment in $R \& D$ and innovations to determine the incentives best suited to overcoming private underinvestment;

- Specify the objectives, design, and timing of particular solar incentives options;

- Analyze the implementation experience of specific solar incentives and design evaluation programs for both proposed and adopted solar incentives; and

- Design model implementation programs, guidelines, standards, regulations, and other initiatives responsive to social, economic, technical, and political considerations.

The research elements should be completed roughly in order so that the last research tasks are informed by the first. However, the immediacy of some solar decisions may foreclose that possibility. Hence, some of the research proposed below may not be informed by useful prior research. Some of the proposed research responds to 
the advocacy element introduced by the urgency and timing of political and social concerns. Such research is distinguishable from other elements of the agenda whose timing depends on technological progress and analytical results of related research tasks.

The first three elements of the research agenda will provide information for use in assessing the types of decisions that energy policymakers will need to make, when those decisions must be made, significant events that may affect the viability and feasibility of each solar technology, the values to society of the solar technology, the desirability of incentives for specific solar technologies at specific points in time, and the likely efficiency of specific incentives.

Other elements in the research agenda concentrate on specific solar objectives, criteria for adopting specific solar incentives, and implementation and evaluation programs for each solar incentive proposed or adopted. In general, the flow of knowledge should be from one element of the research agenda to the next.

\section{THE AGENDA}

1. Specify Social Benefits and Costs of and Underinvestment in Solar Technologies.

Whether government should offer a particular incentive for a particular energy technology or product at a particular time is crucially dependent on the degree to which society's net welfare will be increased by the incentive. In general, an increase in society's net welfare may occur when from a social standpoint there is private underinvestment in the technology (i.e., the social benefits gained from adopting an incentive exceed the social costs). Specifying the nature, cause, and amount of the 
underinvestment helps to identify both the type and the amount of incentives needed.

Many of the benefits of solar implementation are manifested through reduced reliance on and lesser adverse effects associated with other energy technologies. It is thus impossible to confine the research agenda to solar technologies alone. It must be recognized, however, that a technology assessment of just one of the major al ternative "fuel cycles" would absorb many person-years of research effort. It will be necessary for the proposed research agenda to rely on the results of research on alternative energy technologies by other researchers since it will not be practicable to produce them. The results from the second research item below will help to set priorities here, by identifying those conventional technologies where energy displacement by solar is most likely to occur. The objectives of this research are:

- To identify underinvestment in solar technologies and relevant social benefits and social costs attributable to the various solar technologies;

- To quantify underinvestment and social benefits and social costs to the greatest degree possible;

- To identify nonquantifiable social values that will be served by increased use of solar energy; and

- To identify the distribution of social benefits, costs, and values among groups in socicty.

The results of this research are critical to even a rough scoping of the degree of public investment in commercialization incentives that is warranted. 
2. Establish a Strategic Decision-Oriented Framework for Deriving Necessary Incentives Research on Each Solar Technology.

This element in the research agenda is a program of studies of decision points and development events facing each solar technology over the next 15 to 20 years. The objectives of the decision requirements research are:

- To identify critical, non-postponable future decision points, the issues or questions on which such decisions will be based, and the timing of the critical decisions;

- To identify events (e.g., R\&D results) that may necessitate decisions regarding future support (programmatic and budgetary);

- To identify the type of information that will be required to support the decisions;

- To identify the tolerable range of uncertainty of information on which "good" decisions can be based;

- To identify alternative decisions and decision outcomes over t1me; and

- To anticipate and identify the impact of social and political factors which may modify program direction, timing, and objectives.

The results of such a research program will be a description for each solar technology of the timing and nature of critical events, key decision points, information needed at each decision point, and research that must be conducted. An added benefit of this 
approach would be identification of necessary information, quite apart from incentives issues, necessary to formulate and improve long-term strategic planning for each solar technology. The results of this research will provide a setting within which solar incentives for each solar technology can be evaluated.

This research program must be set in terms of specific long-term national energy objectives, identification of specific solar contributions to those objectives, assessment of technical progress likely in each solar technology, and assessments of the possibilities and natures of future critical events. The results for each technology can be visualized in terms of a detailed, time-dated, event-specified, decision tree with probabilities attached to the events. ${ }^{76}$ The final step in this research element would be a comparison and integration of all the solar technology specific studies.

3. Examine Results of Earlier Product Development Efforts To Identify Critical Factors Required in an Incentive.

The third element in the research agenda is a research program that will apply the experience gained from private and public R\&D and commercialization activities to the development and commercialization of solar technologies. Understanding the process, decisions, and timing observed when industry moves a new product from research to development, to pilot plant, to

${ }^{76}$ One possible use of such a collection of research outputs is to answer three questions: (1) How much would it cost to supply $x$ quads of energy from solar technologies by a certain date and how much would each technology contribute? (2) If y billion dollars were available over seven years for deployment, how much energy could solar contribute? and (3) For both cases (1) and (2), what are the critical technical events, supply requirements, and demand attributes? 
demonstration and to market will be useful for governmental decisionmaking as well as formulation of commercialization tactics and incentives. If, as recommended above, the use of government incentives is restricted to those instances where the government can effectively and efficiently improve on private decisions, an understanding of how and why those decisions are made is a critical input to incentive design. Similarly, a review of government's efforts to conduct R\&D and to bring new products to the market (e.g., fish protein concentrate, nuclear ships, the SST, prefabricated housing, and nuclear electricity) should be undertaken. Expectations of the government's performance in solar may be considerably tempered by a review of previous government activities in commercialization. At the least, the design of solar incentives can benefit from previous experience with government stimulation of technology commercialization.

The objectives of the product development review are:

- To study analogous case histories and from those experiences derive improved methods for making shortand long-term decisions with respect to R\&D and commercialization incentives. These methods should be sensitive to prior successes and failures as well as to business management considerations involved in moving new products from laboratory to market;

- To utilize previous experience to design incentives that reflect actual operation of market and nonmarket forces and to better understand behavior responses to. government intervention in energy markets via incentives (subsidies); 
- To identify minimum times that must elapse between sequential decisions (e.g., the time between a pilot plant and a demonstration plant); and

- To identify information sources and needs and set research milestones for the design of technologyspecific incentives over the next five years.

This research program would be coordinated with the studies undertaken in research elements one and two above.

4. Specify the Objectives, Design, and Timing of Solar Incentives.

This research element involves a series of studies to specify for each solar technology a comprehensive set of objectives-technical, economic, social, political, commercial--that incentives could address, as well as the time dimensions associated with implementing those incentives successfully. $\mathrm{Close}$ coordination with the first three research elements will provide critical data on broad program objectives and on information which will be needed to monitor any incentives adopted.

The objectives of this research are:

- To identify specific objectives to be achieved by solar incentives within a specified period of time and a reasonable cost;

- To identify social trends, perspectives, and attitudes indicating ultimate technology acceptance, and thus the potential usefulness of incentives to encourage the development and refinement of specific solar technologies; 
- To develop a decision model for ranking incentives according to technology-specific variables such as technical performance, economic costs, market preferences, social attitudes, comparative energy prices, and end-use requirements. Such rankings would establish a selection basis for incentives appropriate at different stages in the technology development process; and

- To study and compare a variety of incentive designs and preliminarily evaluate their expected performance against the expectations and requirements of DOE and Congress, their abilities to facilitate consideration of solar applications, and the anticipated public response to the incentives.

The results of this research and that of the next element of the agenda will provide a substantial information base for developing the model programs and regulations called for in research element six.

5. Analyze the Implementation Experiences of Existing Solar Incentives and Design Evaluation Programs for Future Incentives.

As federal, state, and local governments pass or approve solar initiatives, their implementation experiences will provide useful information on administrative costs, program difficulties, institutional constraints, and public responses. Since incentives analysis and assessment depend on both a priori and a posteriori evaluations, the issues and costs associated with implementation experience should provide decisionmakers with information needed to improve their programs. 
The objectives of this research are:

- To develop methodologies for determining the efficiency of governments' undertaking solar implementation programs rather than other energy-conserving or supply initiatives;

- To develop from selected solar incentive histories the information needed to improve existing programs or to design effective programs in the future;

- To determine the geographic, educational, economic, and attitudinal characteristics of individuals responding to solar incentives;

- To identify characteristics of various incentives that make them appropriate for implementation at particular levels of government or for particular solar technologies; and

- To undertake evaluation of proposed and adopted solar incentives to determine their useful and effective 1 ifetimes.

Thus, this research agenda will attempt to maximize information obtainable from learning by doing. It will also help establish the monitoring and evaluation activities that will provide feedback for improving solar incentives that have been adopted. 
6. Design Model Solar Incentive Implementation Programs, Guidelines, and Regulations Responsive to Social, Economic, Technical, and Political Issues.

Most of the research elements in this agenda will improve the rationality of decisionmaking processes by structuring them around specific decision points and by developing research information required to support those decisions. Committing substantial resources to analytical research, however, does not eliminate the concomitant responsibility for developing model solar programs in anticipation of Executive, Congressional, or agency decisions to proceed with solar incentives prior to completion of the research agenda. Indeed, the whole point of the research agenda is to anticipate decisions and information needs so that the appropriate research can be undertaken in advance of the decisions.

Policy decisions frequently derive from a host of considerations which may or may not be grounded on deliberate analyses of the costs and benefits of a particular course of action. Legislative or budgetary decisions are often based on reasons that seem "important," responsive to "public opinion," or vaguely desirable or "good." Comprehensive policy analyses thus must satisfy twin objectives: to improve decisionmaking at all levels of government and to anticipate urgent "go ahead" policy decisions with previously designed programs and implementing mechanisms for quick adoption.

In conceding that timeliness is vital in bringing research results to bear on current social, economic, and political issues, one should not ignore the danger that expediency will replace good research and analysis and sound public policymaking. Rather than expediency being allowed to drive public decisions, public policy decisions should be informed by the best available social, behavioral, and physical science information both empirical and 
theoretical. In addition, short-term decisions driven by expediency should to the extent possible be subject to periodic re-examination based on the results of subsequently completed research. Above all, "quick and dirty" analyses should not be allowed to drive out good research in decisionmaking.

The objectives of this research are:

- To identify responses to attitudes and perceptions likely to affect Congressional deliberations and efforts to accelerate development of selected solar technologies in the short term;

- To identify the extent to which federal agency programs and regulations can be used to foster solar development in the short run without creating long-term barriers or entrenched solar bureaucracies;

- To consolidate information (e.g., demonstration, procurement, education, standards) useful in designing model programs and regulations that satisfy short-term criteria selected to assure program effectiveness at reasonable cost; and

- To prepare draft implementation programs, legislation, and other initiatives open to public debate and vigorous analysis to provide policymakers with useful and credible models for accelerating solar technologies. 


\section{SUMMARY}

This chapter provides an agenda of research for improving the quality, timeliness, relevance, and net benefits of incentives for the development and utilization of solar energy. The research agenda is carefully organized to provide a method for (1) determining if 'gaps in knowledge are being filled by appropriate research and (2) relating various pieces of research to an overall structure of the knowledge and research needed for effective solar incentive planning and development. The ordering of the six research elements also reflects an assessment of the priority with which the individual research elements should be undertaken. This specification of priorities along with identification of needed research and the statement of research objections provides the rudiments of a plan for solar incentive development.

No matter how many studies are completed under this research agenda, it is essential that some mechanism be put in place to assure that the studies are done on a consistent, appropriate, and scientifically defensible basis. To date, the mechanism to provide this result has not existed in the national solar program because of limited staff size and budget, and a dearth of social scientists involved in the program who could critically examine the issues surrounding adoption of any energy technology by society. This report has concentrated on producing a research agenda based on identifying research information needed to design appropriate incentives; it is also clear that an institutional mechanism must be found to coordinate and oversee the specific studies that might be undertaken under the proposed research agenda . 